\title{
Urinary Fractional Clearance of Sodium in 8 Healthy Beagle Dogs Fed Normal, Low, or Ultralow Sodium Diets
}

\author{
R. G. Lobetti 10 \\ Bryanston Veterinary Hospital, Box 67092, Bryanston, South Africa \\ Correspondence should be addressed to R. G. Lobetti; rlobetti@mweb.co.za
}

Received 15 October 2019; Revised 10 January 2020; Accepted 11 January 2020; Published 18 February 2020

Academic Editor: Sumanta Nandi

Copyright ( $\odot 2020$ R. G. Lobetti. This is an open access article distributed under the Creative Commons Attribution License, which permits unrestricted use, distribution, and reproduction in any medium, provided the original work is properly cited.

\begin{abstract}
The purpose of this study was to investigate in healthy adult dogs if there was a daily fluctuation in the $\mathrm{FC}_{\mathrm{Na}}$, the role that dietary sodium intake played on the $\mathrm{FC}_{\mathrm{Na}}$, and the role that feeding played on the obtained value for $\mathrm{FC}_{\mathrm{Na}}$. Three different diets were used in a group of 8 healthy beagle dogs in a crossover design. The sodium content of the diets was normal $(0.26 \%)$, low $(0.18 \%)$, and ultralow $(0.06 \%)$. Spot urine and blood samples were collected from which the urine and serum sodium and creatinine concentration were determined, and the $\mathrm{FC}_{\mathrm{Na}}$ was calculated. The median $\mathrm{FC}_{\mathrm{Na}}$ for the normal, low, and ultralow sodium diets was $0.5,0.77$, and 0.15 , respectively. Individual dogs showed a daily variation in $\mathrm{FC}_{\mathrm{Na}}$, and samples which were collected shortly after eating showed the greatest variation. This study showed that in a group of healthy beagle dogs without obvious renal disease, the $\mathrm{FC}_{\mathrm{Na}}$ could exceed 1 and that there was both an individual and daily variation in the $\mathrm{FC}_{\mathrm{Na}}$. The greatest variation was seen whilst the dogs were fed the low and ultralow sodium diets and when the samples were collected shortly after eating. This study concluded that an $\mathrm{FC}_{\mathrm{Na}}>1 \%$ may not be indicative of acute tubular dysfunction in young dogs, and use of the $\mathrm{FC}_{\mathrm{Na}}$ for assessing renal function in clinical cases should take into account the animal's diet, as well as the time the samples were taken in relation to feeding.
\end{abstract}

\section{Introduction}

Fractional clearance is defined as the fraction of the filtered solute that is not reclaimed as it passes through the renal tubular system. In order for the body homeostasis to be maintained, dietary intake needs to be matched by its excretion [1].

In order to maintain a stable plasma composition, the renal tubules either selectively reabsorb filtrate components or they secrete solutes delivered to them by the peritubular circulation [1]. The majority of extracellular sodium is actively reabsorbed in the proximal convoluted tubules [1]. Furthermore, sodium reabsorption takes place in the distal convoluted tubules secondary to active reabsorption of chloride ions and in the collecting ducts, the latter being controlled by the aldosterone [2].

Acute kidney injury (AKI) is a syndrome that is characterized by the sudden onset of impaired renal function resulting in azotaemia, increased fractional clearance of sodium $\left(\mathrm{FC}_{\mathrm{Na}}\right)$, and the presence of renal tubular epithelial cells and/or casts in the urine sediment [3-6]. Fractional excretion of electrolytes has been recently reevaluated in dogs with AKI as a readily available and cost-effective marker of tubular damage and kidney function $[3,5]$. $\mathrm{FC}_{\mathrm{Na}}$ was used as an early and accurate predictor of AKI in a population of dogs with naturally occurring heatstroke despite fluid resuscitation [5]. Although it is generally accepted that a $\mathrm{FC}_{\mathrm{Na}}>1 \%$ is indicative of acute tubular dysfunction [4], an incidental finding in two studies showed that healthy young dogs often had a $\mathrm{FC}_{\mathrm{Na}}>1 \%$ in the absence of obvious signs of renal dysfunction [7, 8]. Another study showed that $\mathrm{FC}_{\mathrm{Na}}$ was not different between volume-responsive AKI and control dogs [6]. These studies attest to the paucity of data in the veterinary literature and the lack of inclusion of healthy control dogs.

It is possible that an $\mathrm{FC}_{\mathrm{Na}}>1 \%$ may not always be indicative of acute tubular dysfunction and that values of this magnitude could merely reflect an increased salt intake by 
TABle 1: Fractional clearance of sodium (FCNa), serum sodium, and urine sodium concentrations in dogs fed normal $(0.26 \%)$, low $(0.18 \%)$, and ultralow $(0.06 \%)$ sodium diets.

\begin{tabular}{lccccc}
\hline & Diets & Mean & Median & SD & Range \\
\hline \multirow{2}{*}{$\mathrm{FC}_{\mathrm{Na}}(\%)$} & Normal & 0.62 & 0.5 & 0.52 & $0-2.69$ \\
& Low & 1.29 & 0.77 & 1.48 & $0.04-8.57$ \\
& Ultra & 0.47 & 0.15 & 0.79 & $0-5.32$ \\
\hline \multirow{2}{*}{$\begin{array}{l}\text { Serum sodium } \\
\text { (mmol/l) }\end{array}$} & Normal & 148.06 & 148 & 1.50 & $144-151$ \\
& Low & 148.93 & 149 & 2.06 & $141-154$ \\
& Ultra & 148.12 & 148 & 2.41 & $141-155$ \\
\hline \multirow{2}{*}{$\begin{array}{l}\text { Urine sodium } \\
\text { (mmol/l) }\end{array}$} & Normal & 61.85 & 50 & 41.03 & $0-180$ \\
& Low & 74 & 70 & 33.63 & $10-200$ \\
& Ultra & 29 & 20 & 35.53 & $0-190$ \\
\hline
\end{tabular}

the animal. In addition, the $\mathrm{FC}_{\mathrm{Na}}$ can also be influenced by the administration of sodium-containing fluids, which can increase the $\mathrm{FC}_{\mathrm{Na}}$ and may negate the usefulness in using $\mathrm{FC}_{\mathrm{Na}}$ as a diagnostic test $[3,5]$.

Feeding has been shown to affect the quantity of sodium that is excreted in the urine of clinically healthy dogs [9]. However, none of the dogs in that study showed an $\mathrm{FC}_{\mathrm{Na}}>1 \%$. In one study in dogs with chronic kidney disease (CKD), the $\mathrm{FC}_{\mathrm{Na}}$ was proportional to the dietary sodium intake [10]. In that study, 3 of the diets were high in sodium $(1.17 \%, 0.95 \%$, and $0.58 \%)$ and 1 had a normal content $(0.25 \%)$ and all dogs had an $\mathrm{FC}_{\mathrm{Na}}<1 \%$. Another study showed that the $\mathrm{FC}_{\mathrm{Na}}$ was higher in dogs with CKD compared to healthy dogs [11]. In the same study, healthy dogs fed either a normal $(0.23 \%)$ or high-sodium $(0.41 \%)$ diet did not have an $\mathrm{FC}_{\mathrm{Na}}>1 \%$ [11]. It has been alluded that prior to determining the fractional clearance of electrolytes, dogs should be fed a consistent diet for approximately 1 week before submission of samples [4].

Although urine collection over a 24-hour period is most accurate for determining the fractional clearance of electrolytes, spot samples of simultaneously collected urine and plasma provide clinically reasonable approximations of total daily excretion despite some variability [4]. Correlation has been shown between spot and 24-hour collection determinations $[12,13]$.

The purpose of this study was to investigate if there was a daily fluctuation in the $\mathrm{FC}_{\mathrm{Na}}$, the role that dietary sodium intake plays on the $\mathrm{FC}_{\mathrm{Na}}$, the role that feeding plays on the obtained value for $\mathrm{FC}_{\mathrm{Na}}$, and whether or not the time of sample collection in relation to feeding can influence $\mathrm{FC}_{\mathrm{Na}}$. The main hypothesis of the study was that an elevated $\mathrm{FC}_{\mathrm{Na}}$ may not be indicative of acute tubular dysfunction if the animal was fed a high-sodium diet.

\section{Materials and Methods}

2.1. Animals. Eight beagles ( 3 males and 5 females) from the Onderstepoort Animal Teaching Unit were used in the study. Seven of the dogs were 6 years of age and one 4 years. Prior to the study, all the dogs were screened for preexisting renal disease by means of full urine analysis and serum biochemistry (urea, creatinine, calcium, phosphate, sodium, and potassium). Fractional clearance of sodium was also determined in all dogs. The dogs were

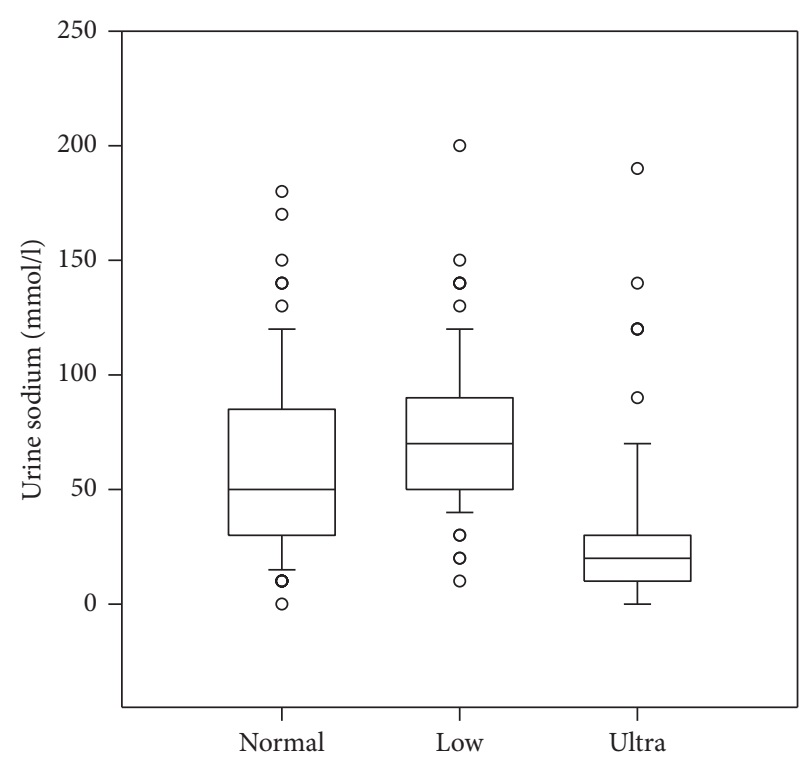

FIgURE 1: Urine sodium concentrations in dogs fed normal $(0.26 \%)$, low $(0.18 \%)$, and ultralow $(0.06 \%)$ sodium diets. Data are shown as median (horizontal line within the box), 25th and 75th percentiles (horizontal ends of boxes), and 10th and 90th percentiles (T-bars). Open circles represent outliers. There was a significant difference between the 3 groups $(p<0.05)$.

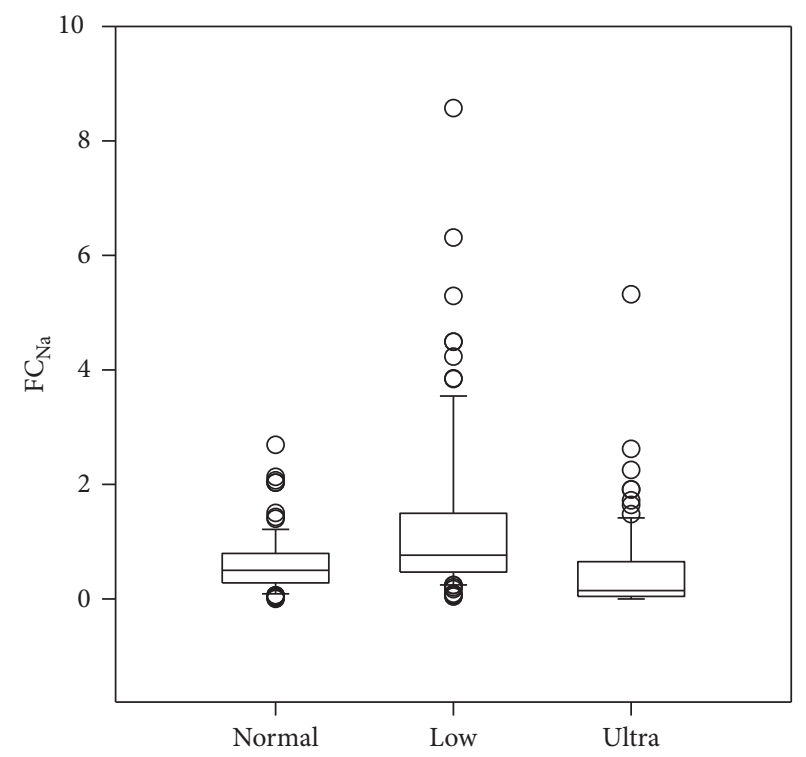

FIgURE 2: Fractional clearance of sodium in dogs fed normal $(0.26 \%)$, low $(0.18 \%)$, and ultralow $(0.06 \%)$ sodium diets. Data are shown as median (horizontal line within box), 25th and 75th percentiles (horizontal ends of boxes), and 10th and 90th percentiles (T-bars). Open circles represent outliers. There was a significant difference between the 3 groups $(p<0.05)$.

kept in an appropriate animal management facility, and the study was approved by the Animal Research and Ethic Committee of the Faculty of Veterinary Science, University of Pretoria. The physical and biochemical examinations performed before the study confirmed that all dogs were healthy. 


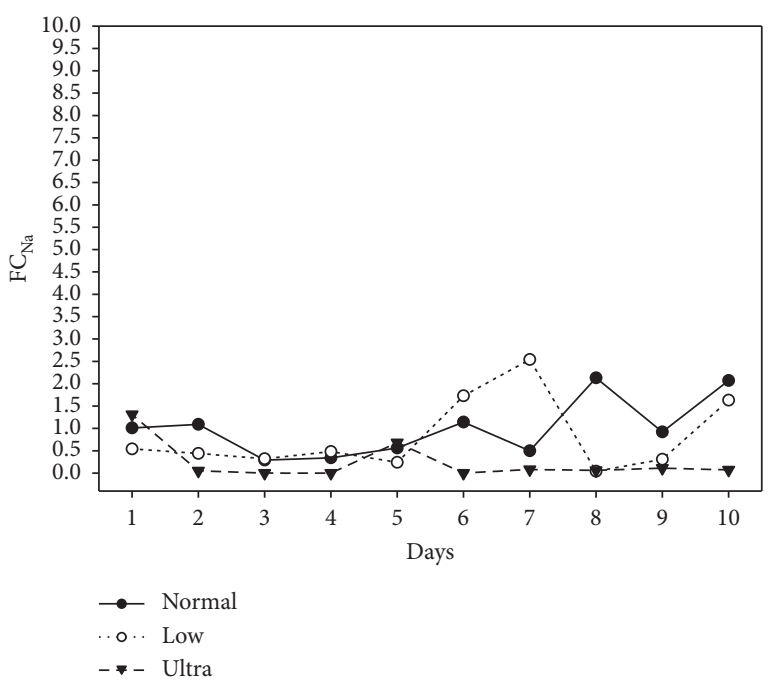

(a)

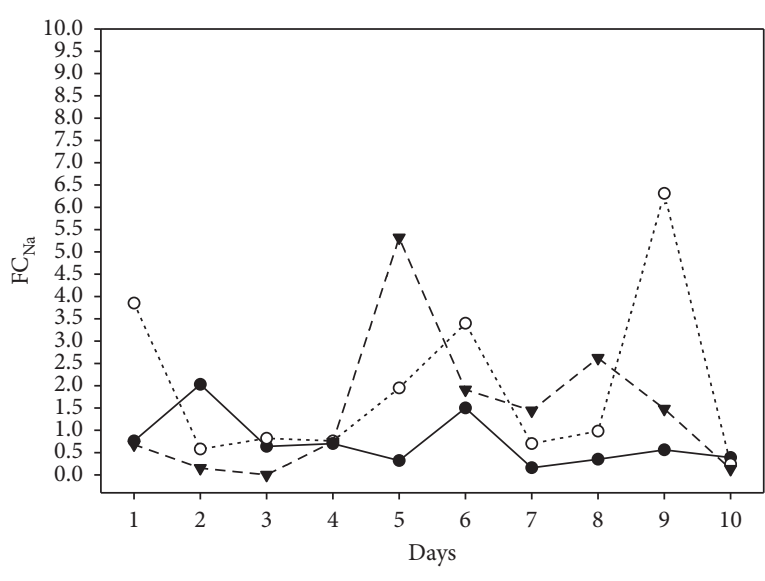

- Normal

o. Low

- - Ultra

(c)

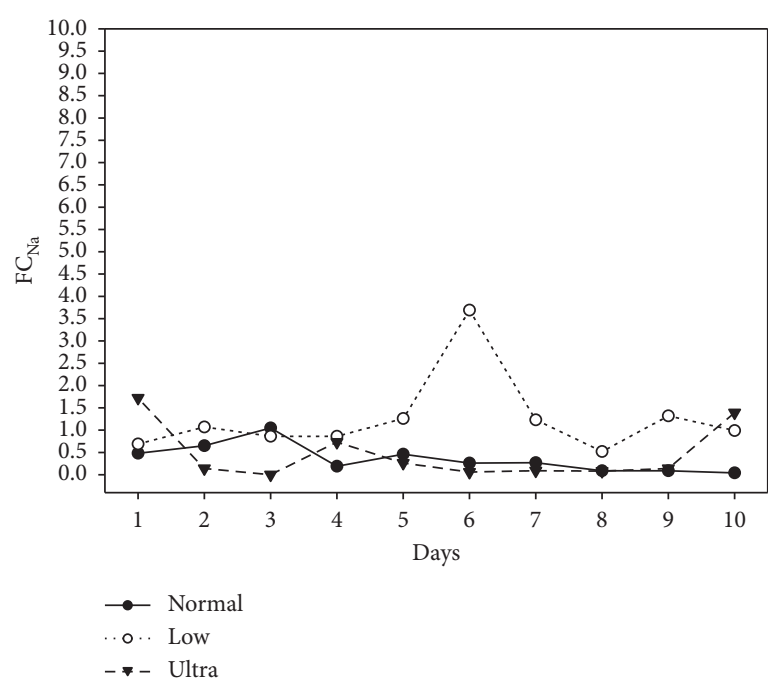

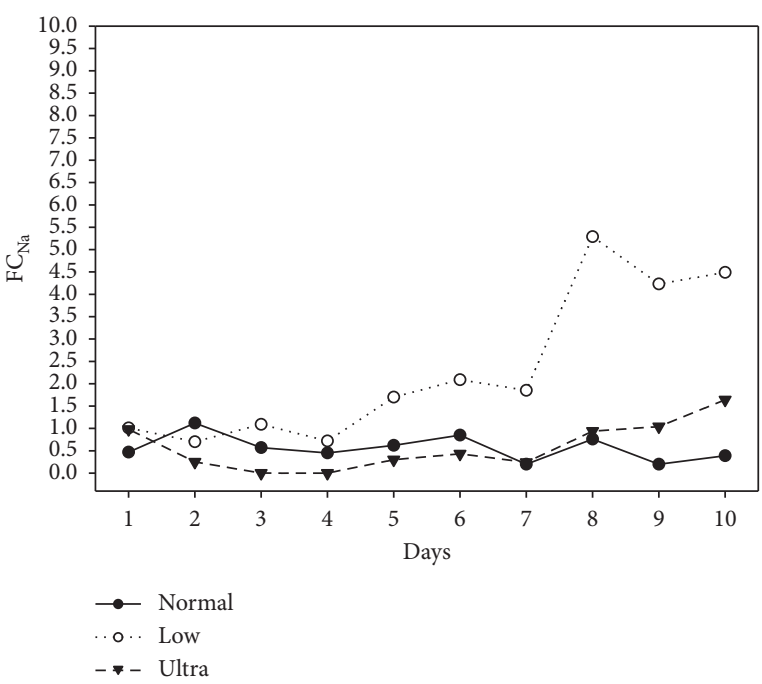

(b)

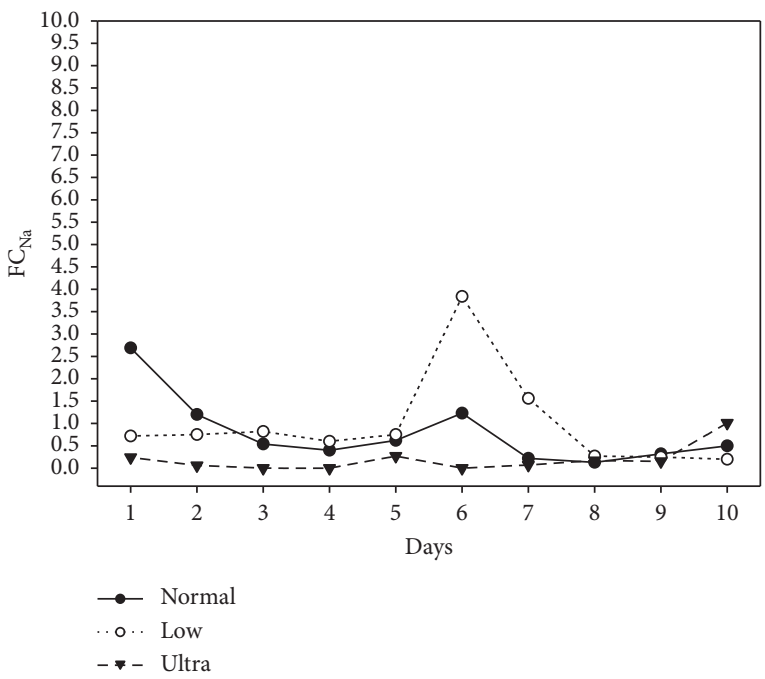

(d)

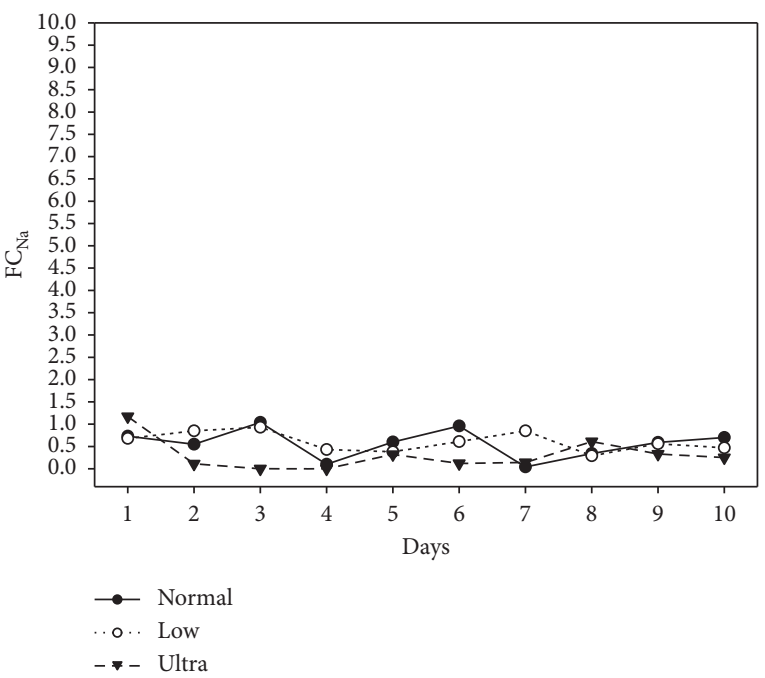

(f)

Figure 3: Continued. 


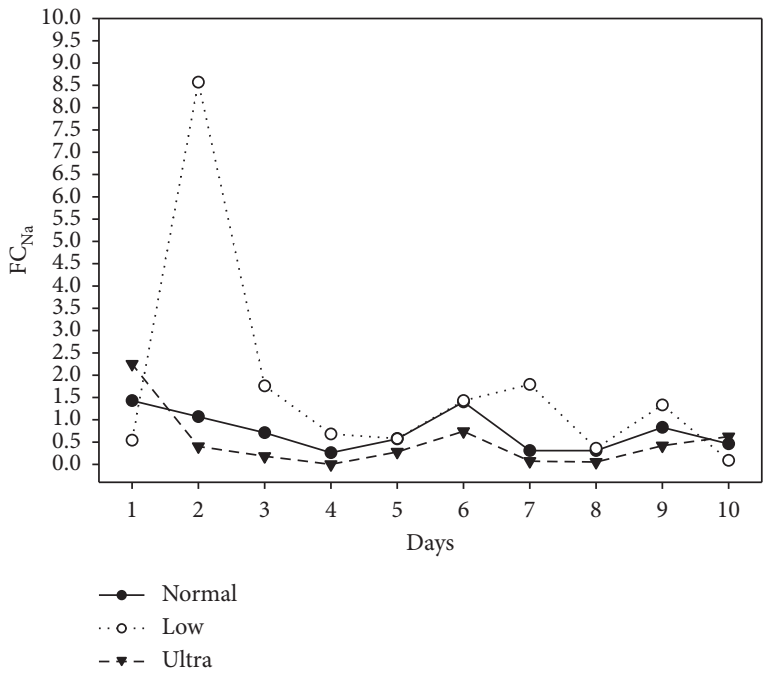

(g)

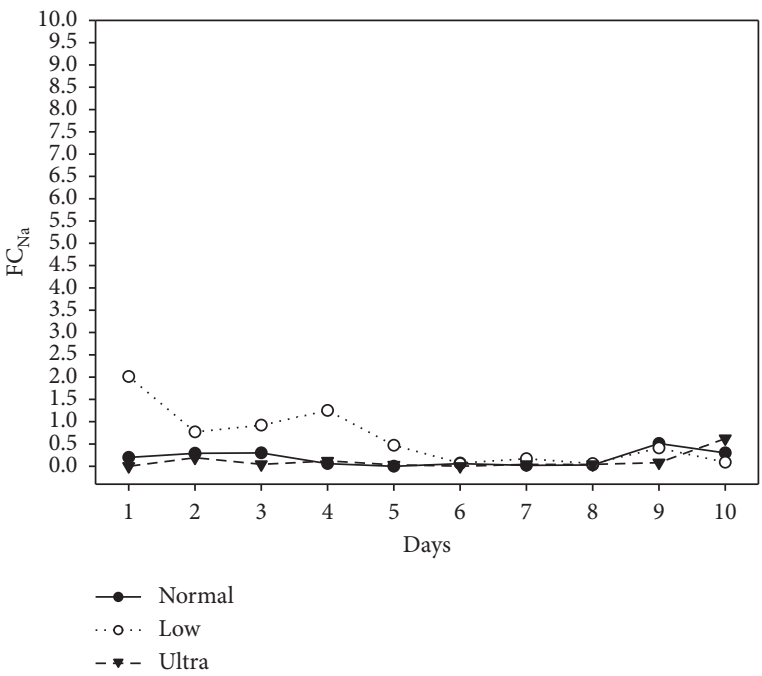

(h)

Figure 3: Individual fractional clearance of sodium over the duration of the study. (a) Dog 1. (b) Dog 2. (c) Dog 3. (d) Dog 4. (e) Dog 5. (f) Dog 6. (g) Dog 7. (h) Dog 8.

2.2. Experimental Procedures. The effect of 3 diets on fractional excretion of sodium was assessed: diet 1 had a normal sodium content (Hills adult maintenance ${ }^{\circledR}, 0.26 \%$ sodium), diet 2 moderately reduced (Hills $\mathrm{k} / \mathrm{d}^{\circledR}, 0.18 \%$ sodium), and diet 3 severely reduced (Hills $\mathrm{h} / \mathrm{d}^{\circledR}, 0.06 \%$ sodium). All dogs and diets were used in a crossover study with a 2-week period being allowed for acclimatisation of the new diet before the samples were collected.

2.3. Data Collection. The dogs were housed in their normal environment, fed twice a day, and had access to ad-lib water. The sodium content in the dogs' drinking water was quantified to be less than $10 \mathrm{mg} / \mathrm{l}$. During the first 2 weeks, no samples were collected from the animals. From the third week onwards, blood and urine samples were collected daily. In the third week, samples were collected after the animals had been fasted for approximately 12-14 hours and in the fourth week samples were collected approximately 2-3 hours after eating. All samples were collected at approximately $10.00 \mathrm{am}$. Serum and urine creatinine were determined on a Technicon RA 1000 system (Technicon Instruments Corporation, Tarrytown, USA). Serum and urine sodium were determined using an ion selective analyzer (Rapidlab ${ }^{\mathrm{TM}} 348$ pH/Blood gas analyzer, Chiron Diagnostics, Essex, UK).

The fractional clearance of sodium was calculated using the following formula:

$\frac{\text { urine sodium }(\mathrm{mmol} / \mathrm{l})}{\operatorname{serum} \operatorname{sodium}(\mathrm{mmol} / \mathrm{l})} \times \frac{\operatorname{serum} \text { creatinine }(\mu \mathrm{mmol} / \mathrm{l})}{\text { urine creatinine }(\mu \mathrm{mmol} / \mathrm{l})} \times 100$.

2.4. Statistical Analysis. Data were tabulated in a spreadsheet program (Excel, Microsoft Corporation, USA). Statistical analysis was performed with the aid of a statistical software package (Sigma Stat, Jandal Corporation, USA), and the generated data were graphically depicted with the aid of a graphic software package (Sigma Plot, Jandal Corporation, USA). Descriptive statistics were used to describe the data with the Kruskal-Wallis one-way analysis of variance on ranks, and the Wilcoxon signed rank test was used to test the statistical difference between groups. The level of significance was set at $p<0.05$.

\section{Results}

The results are tabulated in Table 1 and graphically depicted in Figures 1-3. Median $\mathrm{FC}_{\mathrm{Na}}$ for the normal, low, and ultralow sodium diets was $0.5,0.77$, and 0.15 , respectively, in which there was a statistical difference between the 3 groups. The $\mathrm{FC}_{\mathrm{Na}}$ range for the 3 groups was 0 to 8.57 . Urine sodium values mirrored the $\mathrm{FC}_{\mathrm{Na}}$ results and in that there was a statistical difference between all 3 groups. There was no statistical difference with the serum sodium values between the 3 groups.

Individual dogs showed a daily variation in $\mathrm{FC}_{\mathrm{Na}}$, and samples collected shortly after eating showed the greatest variation.

\section{Discussion}

This study showed that in a group of healthy adult beagle dogs with no evidence of renal dysfunction, $\mathrm{FC}_{\mathrm{Na}}$ could exceed a value of $1 \%$ and that there was both an individual and daily variation. The greatest variation was seen whilst the dogs were fed the low and ultralow sodium diets, but some dogs on the normal sodium diet had sporadic $\mathrm{FC}_{\mathrm{Na}}$ values $>1 \%$. This finding of an $\mathrm{FC}_{\mathrm{Na}}>1 \%$ supports the incidental observation noted in two other studies that healthy young dogs can have $\mathrm{FC}_{\mathrm{Na}}$ values $>1 \%$ with no obvious renal injury $[7,8]$.

This study showed that if samples were collected after food had been withheld for a period of time (12-14 hours), 
there was a tendency for the $\mathrm{FC}_{\mathrm{Na}}$ to be less than $1 \%$ although there was an individual variation. This finding is in agreement with a previous study that showed that in healthy beagle dogs where food was withheld had a significant decrease in urinary excretion of sodium [2]. The dogs in that study were fed a reduced sodium diet $(0.18 \%)$. This finding can be expected as the kidneys primarily eliminate sodium.

In another study in dogs that were fed a normal $(0.23 \%)$ and a high-sodium $(0.41 \%)$ diet, $\mathrm{FC}_{\mathrm{Na}}$ never exceeded $1 \%$ [11]. In this current study, individual dogs fed either the low $(0.18 \%)$ or ultralow $(0.06 \%)$ sodium diet had sporadic $\mathrm{FC}_{\mathrm{Na}}>1 \%$ although the median values for all 3 diets were $<1 \%$. The highest value recorded for the $\mathrm{FC}_{\mathrm{Na}}$ with the normal, low, or ultralow sodium diets, where $2.69,8.57$, and 5.32 , respectively.

This study utilised a spot urine sample to determine the $\mathrm{FC}_{\mathrm{Na}}$, which can be influenced by the circadian variation in the urinary excretion of sodium [11], which was evident in this study by both daily and individual variation. Previous studies have shown correlation between spot and 24-hour collection determinations of $\mathrm{FC}_{\mathrm{Na}}[12,13]$. In a clinical setting, the spot test is more practical than the other 2 collection methods.

This study concluded that an $\mathrm{FC}_{\mathrm{Na}}>1 \%$ may not be indicative of acute tubular dysfunction in young dogs, and use of the $\mathrm{FC}_{\mathrm{Na}}$ for assessing renal function in clinical cases should take into account the animal's diet as well as the time the samples were taken in relation to feeding.

\section{Data Availability}

The raw data used to support the findings of this study are available from the corresponding author upon request.

\section{Conflicts of Interest}

The author declares that there are no conflicts of interest.

\section{Acknowledgments}

The diets used in the study were provided by Hills Pet Foods, South Africa. Funding for the Clinical Pathology tests was covered by the author's research fund, whilst employed at the Department of Companion Animal Medicine, Faculty of Veterinary Science, University of Pretoria.

\section{References}

[1] D. R. Finco, J. A. Barsanti, and S. Brown, "Solute fractional excretion rates," in Current Veterinary Therapy XI, J. D. Bonagura and R. W. Kirk, Eds., pp. 818-820, WB Saunders Company, Philadelphia, PA, USA, 1992.

[2] B. Rivers, P. Walter, T. O'Brien, V. King, and D. Polzin, "Evaluation of urine gamma-glutamyl transpeptidase-tocreatinine ratio as a diagnostic tool in an experimental model of aminoglycoside-induced acute renal failure in the dog," Journal of the American Animal Hospital Association, vol. 32, no. 4, pp. 323-336, 1996.

[3] N. Brown, G. Segev, T. Francey, P. Kass, and L. D. Cowgill, "Glomerular filtration rate, urine production, and fractional clearance of electrolytes in acute kidney Injury in dogs and their association with survival," Journal of Veterinary Internal Medicine, vol. 29, no. 1, pp. 28-34, 2015.

[4] B. M. Pressler, "Clinical approach to advanced renal function testing in dogs and cats," Veterinary Clinics of North America: Small Animal Practice, vol. 43, no. 6, pp. 1193-1208, 2013.

[5] G. Segev, S. Daminet, E. Meyer et al., "Characterization of kidney damage using several renal biomarkers in dogs with naturally occurring heatstroke," The Veterinary Journal, vol. 206, no. 2, pp. 231-235, 2015.

[6] R. Troì, M. Gruarin, C. Grisetti et al., "Fractional excretion of electrolytes in volume-responsive and intrinsic acute kidney injury in dogs: diagnostic and prognostic implications," Journal of Veterinary Internal Medicine, vol. 32, no. 4, pp. 1372-1382, 2018.

[7] R. Lobetti and N. Lambrechts, "Effects of general anesthesia and surgery on renal function in healthy dogs," American Journal of Veterinary Research, vol. 61, no. 2, pp. 121-124, 2000.

[8] R. G. Lobetti and K. E. Joubert, "Effect of administration of nonsteroidal anti-inflammatory drugs before surgery on renal function in clinically normal dogs," American Journal of Veterinary Research, vol. 61, no. 12, pp. 1501-1506, 2000.

[9] J. P. Lulich, C. A. Osborne, and D. J. Polzin, "Urine metabolites in fed and non-fed clinically normal beagles," American Journal of Veterinary Research, vol. 52, pp. 1573-1578, 1991.

[10] K. C. Bovée and D. S. Kronfeld, "Reduction of renal hemodynamics in dogs fed reduced protein diets," Journal of the American Animal Hospital Association, vol. 17, pp. 277-285, 1981.

[11] B. Hansen, S. P. DiBartola, D. J. Chew, C Brownie, and L Nagode, "Clinical and metabolic findings in dogs with chronic renal failure fed two diets," American Journal of Veterinary Research, vol. 53, no. 53, pp. 326-334, 1992.

[12] L. G. Adams, D. J. Polzin, C. A. Osborne, and T. D O’Brien, "Comparison of fractional excretion and 24-hour urinary excretion of sodium and potassium in clinically normal cats and cats with induced chronic renal failure," American Journal of Veterinary Research, vol. 52, no. 52, pp. 718-722, 1991.

[13] D. R. Finco, S. A. Brown, and J. A. Barsanti, "Reliability of using random urine samples for "spot" determination of fractional excretion of electrolytes in cats," American Journal of Veterinary Research, vol. 58, pp. 1184-1187, 1997. 